\title{
Vaccine Development Against Middle East Respiratory Syndrome
}

\author{
Hai Yen Lee 1,2,3 $^{1, \text { Mun Peak Nyon }}{ }^{1,2,3}$ - Ulrich Strych ${ }^{2,3}$
}

Published online: 11 July 2016

(C) Springer International Publishing AG 2016

\begin{abstract}
Various types of vaccines are under pre-clinical and clinical development to address the recent appearance of Middle East respiratory syndrome or MERS, an emerging infectious disease that has already caused over 600 deaths and remains a threat to world health. The causative agent for this respiratory disease is a member of the betacoronavirus genus, phylogenetically closely related to the SARS coronavirus that caused an international health emergency in 2002. With lessons learned from the outbreak of severe acute respiratory syndrome, and with undeniable technological advances, vaccine development against MERS was initially fast-paced and has produced several DNA and protein vaccine candidates with promising results during early pre-clinical testing. At least one vaccine candidate has even entered firstin-humans clinical trials now. With the number of MERS cases declining though and other infectious diseases attracting increased attention, the question remains, whether, similar to the situation after the SARS pandemic, vaccine development is halted or remains the priority it rightfully should.
\end{abstract}

Keywords MERS $\cdot$ SARS $\cdot$ RBD $\cdot$ Vaccines $\cdot$ Coronavirus

Hai Yen Lee and Mun Peak Nyon are joint first authors.

This article is part of the Topical Collection on Viral Tropical Medicine

Ulrich Strych

Strych@bcm.edu

1 Tropical Infectious Diseases Research and Education Centre (TIDREC), University of Malaya, Kuala Lumpur, Malaysia

2 Sabin Vaccine Institute and Texas Children's Hospital Center for Vaccine Development, Houston, TX, USA

3 Department of Pediatrics, National School of Tropical Medicine, Baylor College of Medicine, Houston, TX, USA

\section{Introduction}

Originating in Guangdong Province, China, in 2002, severe acute respiratory syndrome (SARS) became the first pandemic outbreak of the twenty first century. The disease caused over 8000 infections and was responsible for almost 800 deaths. Most remarkably, SARS quickly became a disease of global importance, impacting air travel, commerce, and tourism. While the outbreak was eventually contained using an impressive joint global public health effort, 10 years later, another human coronavirus $(\mathrm{CoV})$ has emerged as the causative agent of Middle East respiratory syndrome (MERS). As of May 2016, there have already been 1728 laboratory confirmed cases of MERS in 27 countries worldwide, with 624 related deaths, 86 of which recorded during an ongoing outbreak in Buraydah, Saudi Arabia [1]. Recurrent episodes like this have impressed upon the scientific community the need to advance development, licensure, manufacture, stockpiling, and deployment of vaccines to combat these emerging infectious coronavirus infections [2]. In this review, the progress in the area of vaccine development for MERS-CoV is appraised, with an assessment of lessons learned from the response to the earlier SARS-CoV pandemic.

\section{Vaccine Development for Coronaviruses}

The Coronavirus family received global attention in November 2002 when the first case of SARS-CoV infection was reported in Guangdong Province, China. Within 3 months, 305 cases with five deaths from respiratory failure had been recorded. This subsequently led to the notification of the World Health Organization (WHO) and the issuance of a global health alert as well as travel advisory. In retrospect, there probably was an initial delay in the identification of this 
etiological agent of unknown origin which consequently allowed the worldwide spread of the disease [3]. The scientific community though was subsequently quick to respond and begin the race towards vaccine development [4]. The full characterization and genome sequencing of SARS-CoV was published within only 2 months after the WHO had started to coordinate the efforts to determine the epidemiology, pathogenesis, and transmission of the disease. Vaccine studies quickly identified the virus' spike (S) protein as a possible recombinant antigen component of a future vaccine, and the Cterminal portion of the SARS-CoV nucleocapsid protein was identified as a likely candidate for improved diagnostics tools. A candidate DNA vaccine showing efficacy in neutralization and protective immunity in mice had been identified within 1 year of the outbreak [5]. Vaccine development was fueled by the daunting possibility of a re-emergence of the disease when additional isolated cases of a suspected SARS infection scare were reported in China in 2004 [6]. At that point, there were ten human vaccine trials planned, using inactivated virus, recombinant proteins, adenovirus platforms, or plasmid DNA. The trials were planned to take place in various countries, including China, Canada, France, Austria, the USA, and Italy [7]. The major hurdle, however, was the lack of an appropriate animal challenge model that could reproduce an infection similar to what was observed in humans. Then, with the identification of virus reservoirs and mechanisms of transmission, the SARS outbreaks ended in July 2003, only 4 months after the issuance of the global alert. The outcomes of this vaccine development race were summarized in a phase I clinical trial report published several years later. Two vaccine candidates were developed and analyzed by Sinovac and the NIH/NIAID, respectively. The earliest live-attenuated vaccine clinical trial that took place under a fast track designation approval from regulatory authorities in China was conducted in 2004 [8, 9]. Results indicated that serum conversion was observed in $100 \%$ of the volunteers who received a low dosage vaccine. In the other study, a plasmid DNA vaccine candidate developed by the NIAID's Vaccine Research Centre was well tolerated and produced the desired immune responses, including neutralizing antibodies [10]. None of the candidates though proceeded into phase II. More recently, a recombinant subunit-based SARS-CoV vaccine was produced by the Sabin Vaccine Institute Product Development Partnership, based on the virus receptor-binding domain [11]. The goal here was to improve safety of the vaccine and cost efficiency of the vaccine development process [12]. The vaccine is being produced under cGMP conditions, but no clinical trials are immediately scheduled.

\section{MERS}

For the Middle East respiratory syndrome (MERS), the first case was reported in June 2012 in Saudi Arabia. This isolate was initially named hCoV-EMC1 and was traced back to a cluster of pneumonia cases in the Zarqa hospital (Jordan) in March/April 2012. In September 2012, a report from the UK about a novel coronavirus (London1) was published, involving a patient with a travel history to Qatar. Shortly thereafter, both isolates were found to be similar, and were named Middle East respiratory syndrome coronavirus (MERS$\mathrm{CoV}$ ), a betacoronavirus phylogenetically closely related to SARS-CoV. By October 2013, there had been 144 laboratory confirmed cases with 17 probable cases affecting nine countries.

Despite increased global vigilance, in part certainly due to the prior experience with SARS-CoV, cases of MERS-CoV were still reported outside the Middle East 3 years after its first emergence. The largest of these was reported in South Korea in June 2015 [13] and was traced back to a single traveler that visited four various Middle Eastern countries. Within a month, this outbreak involved 160 confirmed patients and placed thousands of individuals under close observation [14]. Overall, it is speculated that the lower number of cases of MERS in comparison to SARS may be due to the better coordination of notifications, early travel advisories, the implementation of improved hospital containment measures, the issuance of a global alert by the WHO, and better compliance with International Health Provisions, originally drafted in 2007 [3].

Although there is the possibility that MERS could potentially follow the pandemic path of SARS based on the similarity in phylogenetics, the difference in the biology of the virus and its adaptation to human beings are distinct. While MERS-CoV was found to be already circulating in human populations without mutating into a pandemic form, SARS-CoV adapted to human beings within several months showing the complexity of the virus biology. The affinity of the MERS-CoV spike protein for the human DPP4 receptor is lower than that of the SARS-CoV RBD towards the human ACE-2 receptor and thus the pandemic potential of MERS-CoV has been considered to be lower than that of SARS, likely not reaching epidemic potential [15]. Nevertheless, there remains valid concern especially since its fatality rate of $\sim 36 \%$ is much higher than that for SARS $(\sim 10 \%)$.

\section{Approaches to MERS Vaccine Development}

In Table 1, we summarize the various approaches to developing a MERS-CoV vaccine. 
Table 1 Status of vaccine development approaches against MERS-CoV

\begin{tabular}{|c|c|c|c|c|}
\hline Candidate & Developer & Platform/antigen & Pre-clinical/clinical & Reference \\
\hline GLS-5300 & $\begin{array}{l}\text { Inovio Pharmaceuticals and GeneOne } \\
\text { Life Science Inc }\end{array}$ & Plasmid DNA/full-length S protein & $\begin{array}{l}\text { Mouse, NHP, and camel, } \\
\text { phase I started }\end{array}$ & {$[38 \bullet]$} \\
\hline MVA-MERS-S & $\begin{array}{l}\text { German Center for Infection } \\
\text { Research (DIFZ) }\end{array}$ & $\begin{array}{l}\text { Viral vector modified vaccinia } \\
\text { virus Ankara/full-length S protein }\end{array}$ & Mouse, planning for phase I & {$[44]$} \\
\hline $\begin{array}{l}\text { S protein trimer in } \\
40 \mathrm{~nm} \text { particles }\end{array}$ & Novavax and University of Maryland & Nanoparticles with Matrix M1 adjuvant & Mouse & {$[46]$} \\
\hline $\begin{array}{l}\text { Combined DNA } \\
\text { and protein vaccine }\end{array}$ & Vaccine Research Center, NIAID & $\begin{array}{l}\text { DNA S prime-S1 protein boost } \\
\text { and } \mathrm{S} 1 \text { prime-S1 boost }\end{array}$ & Mouse and NHP & {$[41]$} \\
\hline Receptor-binding domain & New York Blood Center, UTMB, BCM & S377-588 RBD fragment & $\begin{array}{l}\text { Mouse, hDPP4 transgenic } \\
\text { mouse and rabbit }\end{array}$ & {$[31,58 \cdot 61]$} \\
\hline
\end{tabular}

\section{Inactivated and Live-Attenuated Virus}

SARS-CoV, inactivated by means of formaldehyde, UV light, or beta-propiolactone, was able to protect mice from infection in challenge studies [16-18]. In analogy, for MERS, a recombinant, propagation-defective live virus lacking the structural envelope protein gene has been proposed as a vaccine candidate to prevent MERS-CoV infection [19].

\section{MERS-CoV Candidate Vaccine Antigens}

The MERS-CoV genome is approximately $30 \mathrm{~kb}$ in size [20] and encodes several unique accessory proteins and four major structural proteins: the receptor-binding spike $(\mathrm{S})$ protein, a nucleocapsid $(\mathrm{N})$ protein, an envelope $(\mathrm{E})$ protein, and the membrane $(\mathrm{M})$ protein [21]. The initial expectation that the host cell entry point for MERS-CoV would be similar to the angiotensin-converting enzyme 2 (ACE2) receptor used by SARS-CoV was not confirmed. Instead, the dipeptidyl peptidase-4 (DPP4) receptor was identified as the critical receptor for entry of MERS-CoV into its host cell [22]. DPP4 does not share any structural similarities to ACE2 and has a more diverse cellular tropism as it is expressed on the surface of several types of cells [23]. While SARS-CoV specifically targets ACE2-expressing ciliated epithelial cells in the lungs $[24,25]$, DPP4 plays a more diverse role including in the regulation of peptide hormone metabolism, $\mathrm{T}$ cell activation, neurotransmitter function, and glucose homeostasis [26]. Notably, the MERS-CoV spike protein exhibits a high affinity for DPP4 receptors from a wide range of hosts, including human, camel, and horse [27].

\section{Receptor-Binding Domain-Based Vaccine Candidates}

The 193 amino acid residue receptor-binding domain (RBD) fragment of the S1 subunit of the SARS-CoV spike protein was able to induce neutralizing antibodies and protect against SARS-CoV infection in animal models [28, 29]. Using homology modeling, the corresponding MERS-CoV RBD was located between residues 377 to 662 in the $S$ protein [30•].
Several variants of the RBD have since been investigated as vaccine candidates with the S377-588 fragment (fused to human $\mathrm{IgG} \mathrm{Fc}$ ) demonstrating the highest DPP4-binding affinity and inducing the highest titers of neutralizing antibodies in immunized mice and rabbits [31]. Another RBD fragment, S367-606, formulated with aluminum hydroxide (alum) has been investigated in a rhesus macaque model [32]. Animals immunized with a higher dose of the vaccine $(200 / 100 / 100 \mu \mathrm{g}$ rRBD admixed with $1 \mathrm{mg}$ of alum adjuvant) showed less severe pneumonia and decreased viral loads upon challenge with MERS-CoV, compared to a lower dose group [32].

Recently though, a group in Korea observed a high mutation rate in isolates of the MERS-CoV from several patients. It was seen that these mutations in the RBD of the $\mathrm{S}$ protein displayed reduced binding affinity to their host cell receptor, making the virus less virulent than the wild-type, but possibly also contributing to the virus evading the host immune system. [33]. Therefore, Shi et al. suggested epitope-based vaccine design to identify highly conserved region that can produce neutralizing antibodies and cellular immunity against MERS$\mathrm{CoV}$. Based on the in silico protein antigenic prediction and structure analysis, nucleocapsid $(\mathrm{N})$ protein of MERS-CoV was the most probable antigenic protein and a number of putative lymphocytes epitope peptides were identified from the $\mathrm{N}$ protein [34]. Nevertheless, these suggested epitopes have to undergo comprehensive in vitro and in vivo studies for their efficient use as vaccines against MERS-CoV.

\section{DNA Vaccines}

The use of DNA vaccines is based on the transfection of plasmid DNA that encodes antigenic proteins into host cells and the subsequent expression of these foreign genes in order to induce a potent immune response against the disease of interest. Undoubtedly, at first glance, nucleic acid immunization appears to be an attractive vaccine platform: fast vaccine development, a clean safety profile, and low production costs [35]. However, in spite of the promising data from preclinical animal studies, DNA vaccines have not yet been fully successful in humans. For example, the dengue DNA vaccine 
$\mathrm{D}_{\mathrm{M}} \mathrm{ME}^{100}$ showed excellent anti-dengue cellular and humoral immune responses in non-human primates; however, it failed to produce neutralizing antibody in human subjects [36, 37]. Research and development on MERS$\mathrm{CoV}$ DNA vaccines has been focused on the $\mathrm{S}$ protein by engineering plasmid DNA that encoded full-length $\mathrm{S}$ protein sequences [38•]. A synthetic DNA vaccine against MERS-CoV was studied in mice and large animal models (non-human primates-NHPs and camels), and the results showed that the vaccine is capable of inducing $\mathrm{S}$ protein-specific neutralizing antibodies in these animals. Intriguingly, the study revealed that vaccinated NHPs were protected and failed to demonstrate any clinical or radiographic signs of pneumonia post MERS viral challenge [38•]. In early 2016, the first-inhuman trial of MERS vaccine has begun [39], where 75 participants will receive the MERS DNA vaccine, GLS5300, co-developed by Inovio Pharmaceuticals and GeneOne Life Science Inc. [40]. In an alternative approach, Graham and co-workers proposed to combine a DNA vaccine and the S1 subunit protein in a primeboost scheme. Rhesus macaques immunized with spike DNA vaccine followed by the S1 protein (adjuvanted with aluminum phosphate) yielded more neutralizing antibodies, showed fewer signs of pulmonary disease than animals vaccinated with the S1 protein only [41].

\section{Viral Vector-Based Vaccines}

A MERS-CoV vaccine that targets camels has been developed using viral vector vaccine technology, with adenoviral vectors encoding the full-length MERS-CoV S protein or the S1 extracellular domain of S protein. Pre-clinical studies showed vaccinated dromedary camels had mounted a neutralizing antibody response against MERS-CoV in vitro [42]. Guo et al. highlighted that the intramuscular route for administering adenovirus-based vaccines (with MERS-CoV S protein) could affect the antigen-specific $T$ cell response in immunized mice [43•]. Lately, viral vector vaccines against MERS-CoV have been constructed using modified vaccinia virus Ankara (MVA). The MVA-MERS$\mathrm{S}$ recombinant virus, which is genetically stable in primary chicken embryo fibroblasts (CEF) without the need for additional animal-derived components, was able to protect human DPP4-transduced mice against MERS-CoV challenge [44]. The phase I clinical trial in humans of this vaccine has been announced and is supported by the German Center for Infection Research, DIFZ [45].

\section{Nanoparticle Vaccines}

Novavax, in collaboration with a team from the University of Maryland, has produced MERS-CoV full-length nanosized, amphiphilic spike protein aggregates using a recombinant baculovirus construct in Sf9 cells. When formulated with alum, or, to an even greater extent, Novavax' saponin-based matrix-M1 adjuvant, high titers of neutralizing antibodies against MERS-CoV (but the related SARS-CoV) were observed [46]. However, no plans for clinical trials have been made public yet [47].

\section{A Vaccine for Camels}

Another approach towards a MERS vaccine is targeting camels, one of the reservoirs of the virus. According to a cross-sectional serological survey in all 13 provinces of Saudi Arabia ( 10,000 individuals), the seroprevalence of MERS-CoV antibodies was significantly higher in camel-exposed individuals than in the general population [48]. Scientists from The Netherlands, Germany, and Spain have shown that a modified vaccinia virus Ankara vaccine expressing the MERS-CoV spike protein (MVA-S) conferred mucosal immunity in dromedary camels. Using a prime-boost approach, dromedary camels were immunized intranasally as well as intramuscularly, and, after 3 weeks, challenged intranasally with MERS-CoV virus. While the animals showed the typical mild clinical symptoms of a MERS infection in this species, a significant reduction of excreted infectious virus particles, as well as a reduction of viral RNA in immunized camels was observed [49, 50•]. However, there is concern that this reduction might not be sufficient to disrupt the spread of the virus, or that the vaccination might not provide long-lasting immunity. In addition, since the disease does not cause any significant morbidity in camels, there is perceived reluctance among camel owners to have their animals vaccinated in the first place [51]. As an added benefit of the MVA-S vaccine though, it was observed that the vaccination provided cross-protection against camelpox virus, which might the treatment more attractive to the animal owners.

\section{Animal Models for MERS Vaccine Testing}

In order to characterize the viral pathogenesis and evaluate therapeutic options for MERS-CoV, researchers rely on an animal model mimicking the clinical course and pathology observed in humans. In contrast to the SARS animal model, where aged mice displayed pathological changes post-infection [52], mice infected with MERS$\mathrm{CoV}$ did not show any clinical signs of infections, such as weight loss [53]. In addition, Syrian hamsters and ferrets, which are known to be susceptible to SARS$\mathrm{CoV}$, failed to be infected by MERS-CoV [22, 54]. 
Non-human primates (NHP) and common marmoset models have been tested for their suitability as MERS$\mathrm{CoV}$ models. Upon a combination of various inoculation routes (intratracheal, ocular, oral, and intranasal) using an infectious dose of MERS-CoV, rhesus macaques developed a transient lower respiratory tract infection and mild clinical disease without mortality [55]. On the other hand, MERS-CoV infected common marmosets developed progressive, severe pneumonia [56]. Although NHPs are sufficiently good models to study MERS at different severity, working with NHPs is costly. Hence, establishing transgenic rodent animal models is crucial to move forward in the development of vaccines and therapeutic methods against MERS-CoV. By comparing small animal cell lines transfected with human and hamster dpp 4 genes, it was observed that only humanized cell lines enabled MERS-CoV replication [57]. Therefore, researchers have now developed a hDPP4 transgenic mouse model $[58 \bullet, 59]$. Agrawal et al. cloned hCD26/DPP4 in an expression vector with the ubiquitous cytomegalovirus immediate early enhancer and chicken beta-actin promoter and microinjected the DNA into mice zygotes. After lineage screening, hDPP4 transgenic mice that expressed hCD26/DPP4 were fully permissive to MERS-CoV infection, resulting in weight loss and an acute inflammatory response within the lungs and brains of the animal [58•]. When these hCD26/DPP4 transgenic mice were immunized with MF59-adjuvanted RBD fragment (S377-588), fused to the Fc fragment, they were protected after challenge with a high dose $\left(100 \times L_{50}\right)$ of the virus [60]. Another hDPP4 transgenic mouse was recently created using an expression vector with either cytokeratin 18 (K18) or surfactant protein C (SPC) promoters, with the SPC-DPP4 transgenic mice exhibiting a milder disease phenotype [59].

\section{Conclusion}

Emerging and re-emerging diseases with pandemic potential are a major driving force for vaccine development. For human coronaviruses, the pandemic outbreak of SARS-CoV necessitated the development of a blueprint for a global response to this type of threat. As MERS-CoV reaches the fourth year of its emergence, initial technological advances have enabled one DNA-based vaccine to quickly enter phase I human trials. The process was arguably accelerated by key information for strategic vaccine development obtained during the prior SARS-CoV outbreak. Nevertheless, the process of bringing a vaccine to the clinic remains lengthy and cumbersome, and with new infectious diseases shifting the focus away from MERS, there is the risk that, just as before, the vaccine development process remains unfinished and is only picked up again when the next coronavirus emerges.

\section{Compliance with Ethical Standards}

Conflict of Interest The authors declare that they have no conflict of interest.

Human and Animal Rights and Informed Consent This article does not contain any studies with human or animal subjects performed by any of the authors.

\section{References}

Papers of particular interest, published recently, have been highlighted as:

- Of importance

1. WHO. Middle East Respiratory syndrome coronavirus (MERSCoV)—Saudi Arabia. 2016. http://www.who.int/csr/don/23march-2016-mers-saudi-arabia/en/. Accessed 13 May 2016.

2. De Groot AS, Einck L, Moise L, Chambers M, Ballantyne J, Malone RW, et al. Making vaccines "on demand": a potential solution for emerging pathogens and biodefense? Human vaccines \& immunotherapeutics. 2013;9(9):1877-84. doi:10.4161/hv.25611.

3. Heymann DL, Mackenzie JS, Peiris M. SARS legacy: outbreak reporting is expected and respected. The Lancet. 381(9869):779 81. doi:10.1016/s0140-6736(13)60185-3.

4. Viret J-F, Glück R, Moser C. Development of a SARS vaccine: an industrial perspective on the global race against a global disease. Expert review of vaccines. 2003;2(4):465-7. doi: 10.1586/14760584.2.4.465.

5. Yang Z-y, Kong W-p, Huang Y, Roberts A, Murphy BR, Subbarao $\mathrm{K}$, et al. A DNA vaccine induces SARS coronavirus neutralization and protective immunity in mice. Nature. 2004;428(6982):561-4.

6. Fleck F. SARS virus returns to China as scientists race to find effective vaccine. Bulletin of the World Health Organization. 2004;82:152-3.

7. Marshall E, Enserink M. Caution urged on SARS vaccines. Science. 2004;303(5660):944-6. doi:10.1126/science.303.5660.944.

8. Wire B. Sinovac Biotech Ltd releases further results from SARS vaccine phase I human clinical trial. 2004. http://www. businesswire.com/news/home/20041213005499/en/SinovacBiotech-Ltd.-Releases-Results-SARS-Vaccine. Accessed 20 April 2016.

9. Lin JT, Zhang JS, Su N, Xu JG, Wang N, Chen JT, et al. Safety and immunogenicity from a phase I trial of inactivated severe acute respiratory syndrome coronavirus vaccine. Antiviral therapy. 2007;12(7):1107-13.

10. Martin JE, Louder MK, Holman LA, Gordon IJ, Enama ME, Larkin BD, et al. A SARS DNA vaccine induces neutralizing antibody and cellular immune responses in healthy adults in a phase I clinical trial. Vaccine. 2008;26(50):6338-43.

11. Chen W-H, Du L, Chag SM, Ma C, Tricoche N, Tao X, et al. Yeastexpressed recombinant protein of the receptor-binding domain in SARS-CoV spike protein with deglycosylated forms as a SARS vaccine candidate. Human vaccines \& immunotherapeutics. 2014;10(3):648-58. 
12. Jiang S, Bottazzi ME, Du L, Lustigman S, Tseng C-TK, Curti E, et al. Roadmap to developing a recombinant coronavirus $\mathrm{S}$ protein receptor-binding domain vaccine for severe acute respiratory syndrome. Expert review of vaccines. 2012;11(12):1405-13. doi:10.1586/erv.12.126.

13. WHO. MERS-CoV outbreak largest outside Kingdom of Saudi Arabia assessed on June 2, 2015. 2015. http://www.who. $\mathrm{int} /$ mediacentre/news/situation-assessments/2-june-2015-republicof-korea/en/. Accessed 29 March 2016.

14. Kim JI, Kim Y-J, Lemey P, Lee I, Park S, Bae J-Y, et al. The recent ancestry of Middle East respiratory syndrome coronavirus in Korea has been shaped by recombination. Scientific Reports. 2016;6: 18825 .

15. Breban R, Riou J, Fontanet A. Interhuman transmissibility of Middle East respiratory syndrome coronavirus: estimation of pandemic risk. The Lancet. 382(9893):694-9. doi:10.1016/s01406736(13)61492-0.

16. Bolles M, Deming D, Long K, Agnihothram S, Whitmore A, Ferris $\mathrm{M}$, et al. A double-inactivated severe acute respiratory syndrome coronavirus vaccine provides incomplete protection in mice and induces increased eosinophilic proinflammatory pulmonary response upon challenge. Journal of virology. 2011;85(23):1220115. doi:10.1128/JVI.06048-11.

17. Jiang $\mathrm{S}, \mathrm{He} \mathrm{Y}$, Liu S. SARS vaccine development. Emerging infectious diseases. 2005;11(7):1016-20. doi:10.3201/eid1107.050219.

18. Jimenez-Guardeno JM, Regla-Nava JA, Nieto-Torres JL, DeDiego ML, Castano-Rodriguez C, Fernandez-Delgado R, et al. Identification of the mechanisms causing reversion to virulence in an attenuated SARS-CoV for the design of a genetically stable vaccine. PLoS pathogens. 2015;11(10):e1005215. doi:10.1371/journal.ppat.1005215.

19. Almazan F, DeDiego ML, Sola I, Zuniga S, Nieto-Torres JL, Marquez-Jurado S, et al. Engineering a replication-competent, propagation-defective Middle East respiratory syndrome coronavirus as a vaccine candidate. mBio. 2013;4(5):e00650-13. doi:10.1128/mBio.00650-13.

20. Boheemen S, Graaf M, Lauber C, Bestebroer TM, Raj VS, Zaki $\mathrm{AM}$, et al. Genomic characterization of a newly discovered coronavirus associated with acute respiratory distress syndrome in humans. mBio. 2012;3(6):e00473-12.

21. Yang Y, Zhang L, Geng H, Deng Y, Huang B, Guo Y, et al. The structural and accessory proteins M, ORF 4a, ORF 4b, and ORF 5 of Middle East respiratory syndrome coronavirus (MERS-CoV) are potent interferon antagonists. Protein \& cell. 2013;4(12):951-61. doi:10.1007/s13238-013-3096-8.

22. Raj VS, Smits SL, Provacia LB, van den Brand JM, Wiersma L, Ouwendijk WJ, et al. Adenosine deaminase acts as a natural antagonist for dipeptidyl peptidase 4-mediated entry of the Middle East respiratory syndrome coronavirus. Journal of virology. 2014;88(3): 1834-8. doi:10.1128/JVI.02935-13.

23. Gallagher T, Perlman S. Public health: broad reception for coronavirus. Nature. 2013;495(7440):176-7.

24. Kuba K, Imai Y, Rao S, Gao H, Guo F, Guan B, et al. A crucial role of angiotensin converting enzyme 2 (ACE2) in SARS coronavirusinduced lung injury. Nature medicine. 2005;11(8):875-9.

25. Li W, Moore MJ, Vasilieva N, Sui J, Wong SK, Berne MA, et al. Angiotensin-converting enzyme 2 is a functional receptor for the SARS coronavirus. Nature. 2003;426(6965):450-4.

26. Hildebrandt M, Reutter W, Arck P, Rose M, Klapp BF. A guardian angel: the involvement of dipeptidyl peptidase IV in psychoneuroendocrine function, nutrition and immune defence. Clinical Science. 2000;99(2):93-104. doi:10.1042/cs0990093.

27. Barlan A, Zhao J, Sarkar MK, Li K, McCray PB, Perlman S, et al. Receptor variation and susceptibility to Middle East respiratory syndrome coronavirus infection. Journal of virology. 2014;88(9): 4953-61. doi:10.1128/jvi.00161-14.
28. Wong SK, Li W, Moore MJ, Choe H, Farzan M. A 193-amino acid fragment of the SARS coronavirus S protein efficiently binds angiotensin-converting enzyme 2 . The Journal of biological chemistry. 2004;279(5):3197-201. doi:10.1074/jbc.C300520200.

29. Du L, Zhao G, He Y, Guo Y, Zheng BJ, Jiang S, et al. Receptorbinding domain of SARS-CoV spike protein induces long-term protective immunity in an animal model. Vaccine. 2007;25(15): 2832-8. doi:10.1016/j.vaccine.2006.10.031.

30. Du L, Zhao G, Kou Z, Ma C, Sun S, Poon VK, et al. Identification of a receptor-binding domain in the $\mathrm{S}$ protein of the novel human coronavirus Middle East respiratory syndrome coronavirus as an essential target for vaccine development. Journal of virology. 2013;87(17):9939-42. doi:10.1128/JVI.01048-13. Description of the performance of an RBD-based MERS vaccine.

31. Ma C, Wang L, Tao X, Zhang N, Yang Y, Tseng CT, et al. Searching for an ideal vaccine candidate among different MERS coronavirus receptor-binding fragments - the importance of immunofocusing in subunit vaccine design. Vaccine. 2014;32(46):6170-6. doi:10.1016/j.vaccine.2014.08.086.

32. Lan J, Yao Y, Deng Y, Chen H, Lu G, Wang W, et al. Recombinant receptor binding domain protein induces partial protective immunity in rhesus macaques against Middle East respiratory syndrome coronavirus challenge. EBioMedicine. 2015;2(10):1438-46. doi:10.1016/j.ebiom.2015.08.031.

33. Kim Y, Cheon S, Min CK, Sohn KM, Kang YJ, Cha YJ, et al. Spread of mutant Middle East respiratory syndrome coronavirus with reduced affinity to human CD26 during the South Korean outbreak. mBio. 2016;7(2): doi:10.1128/mBio.00019-16.

34. Shi J, Zhang J, Li S, Sun J, Teng Y, Wu M, et al. Epitope-based vaccine target screening against highly pathogenic MERS-CoV: an in silico approach applied to emerging infectious diseases. PloS one. 2015;10(12):e0144475. doi:10.1371/journal.pone.0144475.

35. Tregoning JS, Kinnear E. Using plasmids as DNA vaccines for infectious diseases. Microbiology spectrum. 2014;2(6): doi:10.1128/microbiolspec.PLAS-0028-2014.

36. Beckett CG, Tjaden J, Burgess T, Danko JR, Tamminga C, Simmons M, et al. Evaluation of a prototype dengue-1 DNA vaccine in a phase 1 clinical trial. Vaccine. 2011;29(5):960-8. doi:10.1016/j.vaccine.2010.11.050.

37. Porter KR, Raviprakash K. Nucleic acid (DNA) immunization as a platform for dengue vaccine development. Vaccine. 2015;33(50): 7135-40. doi:10.1016/j.vaccine.2015.09.102.

38. Muthumani K, Falzarano D, Reuschel EL, Tingey C, Flingai S, Villarreal DO, et al. A synthetic consensus anti-spike protein DNA vaccine induces protective immunity against Middle East respiratory syndrome coronavirus in nonhuman primates. Science translational medicine. 2015;7(301):301ra132. doi:10.1126/scitranslmed.aac7462. Initial demonstration that a DNA vaccine provides protection from MERS infection in Non Human Primates.

39. Clinical_Trials.gov. Phase I, open label dose ranging safety study of GLS-5300 in healthy volunteers. 2016. https://clinicaltrials.gov/ct2 /show/NCT02670187?term=GLS-5300\&rank=1.

40. First-in-man trial of MERS vaccine begins. Medical Express. 2016. $\mathrm{http} / / /$ medicalxpress.com/news/2016-02-first-in-man-trial-mersvaccine.html. Accessed 10 March 20162016.

41. Wang L, Shi W, Joyce MG, Modjarrad K, Zhang Y, Leung K, et al. Evaluation of candidate vaccine approaches for MERS-CoV. Nature communications. 2015;6:7712. doi:10.1038/ncomms8712.

42. Kim E, Okada K, Kenniston T, Raj VS, AlHajri MM, Farag EA, et al. Immunogenicity of an adenoviral-based Middle East respiratory syndrome coronavirus vaccine in BALB/c mice. Vaccine. 2014;32(45):5975-82. doi:10.1016/j.vaccine.2014.08.058.

43. Guo X, Deng Y, Chen H, Lan J, Wang W, Zou X, et al. Systemic and mucosal immunity in mice elicited by a single immunization with human adenovirus type 5 or 41 vector-based 
vaccines carrying the spike protein of Middle East respiratory syndrome coronavirus. Immunology. 2015;145(4):476-84. doi:10.1111/imm.12462. Study describing an adenovirusbased vaccine candidate for MERS.

44. Volz A, Kupke A, Song F, Jany S, Fux R, Shams-Eldin H, et al. Protective efficacy of recombinant modified vaccinia virus Ankara delivering middle east respiratory syndrome coronavirus spike glycoprotein. Journal of virology. 2015;89(16):8651-6. doi:10.1128/JVI.00614-15.

45. Planning for first clinical trial of MERS-CoV vaccine candidate now underway. News Medical. 2015. http://www.news-medical. net/news/20150622/Planning-for-first-clinical-trial-of-MERS$\mathrm{CoV}$-vaccine-candidate-now-underway.aspx. Accessed 16 March 2016.

46. Coleman CM, Liu YV, Mu H, Taylor JK, Massare M, Flyer DC, et al. Purified coronavirus spike protein nanoparticles induce coronavirus neutralizing antibodies in mice. Vaccine. 2014;32(26): 3169-74. doi:10.1016/j.vaccine.2014.04.016.

47. Novavax. Clinical stage pipeline. 2016. http://novavax. com/page/11/clinical-stage-pipeline. Accessed 03/22/2016.

48. Muller MA, Meyer B, Corman VM, Al-Masri M, Turkestani A, Ritz D, et al. Presence of Middle East respiratory syndrome coronavirus antibodies in Saudi Arabia: a nationwide, cross-sectional, serological study. The Lancet Infectious diseases. 2015;15(6):629. doi:10.1016/S1473-3099(15)00029-8.

49. Song F, Fux R, Provacia LB, Volz A, Eickmann M, Becker S, et al. Middle East respiratory syndrome coronavirus spike protein delivered by modified vaccinia virus Ankara efficiently induces virusneutralizing antibodies. Journal of virology. 2013;87(21):11950-4. doi:10.1128/JVI.01672-13.

50. Haagmans BL, van den Brand JM, Raj VS, Volz A, Wohlsein P, Smits SL, et al. An orthopoxvirus-based vaccine reduces virus excretion after MERS-CoV infection in dromedary camels. Science. 2016;351(6268):77-81. doi:10.1126/science.aad1283. Article summarizing the state of the art for MERS vaccines in camels.

51. Kupferschmidt K. Infectious disease. Camel vaccine offers hope to stop MERS. Science. 2015;350(6267):1453. doi:10.1126 /science.350.6267.1453.

52. Roberts A, Paddock C, Vogel L, Butler E, Zaki S, Subbarao K. Aged BALB/c mice as a model for increased severity of severe acute respiratory syndrome in elderly humans. Journal of virology. 2005;79(9):5833-8. doi:10.1128/JVI.79.9.5833-5838.2005.

53. Coleman CM, Matthews KL, Goicochea L, Frieman MB. Wild-type and innate immune-deficient mice are not susceptible to the Middle East respiratory syndrome coronavirus. The Journal of general virology. 2014;95(Pt 2):408 12. doi:10.1099/vir.0.060640-0.

54. de Wit E, Prescott J, Baseler L, Bushmaker T, Thomas T, Lackemeyer MG, et al. The Middle East respiratory syndrome coronavirus (MERS-CoV) does not replicate in Syrian hamsters. PloS one. 2013;8(7):e69127. doi:10.1371/journal.pone.0069127.

55. de Wit E, Rasmussen AL, Falzarano D, Bushmaker T, Feldmann F, Brining DL, et al. Middle East respiratory syndrome coronavirus (MERS-CoV) causes transient lower respiratory tract infection in rhesus macaques. Proceedings of the National Academy of Sciences of the United States of America. 2013;110(41):16598603. doi:10.1073/pnas. 1310744110.

56. Falzarano D, de Wit E, Feldmann F, Rasmussen AL, Okumura A, Peng X, et al. Infection with MERS-CoV causes lethal pneumonia in the common marmoset. PLoS pathogens. 2014;10(8):e1004250. doi:10.1371/journal.ppat.1004250.

57. van Doremalen N, Miazgowicz KL, Milne-Price S, Bushmaker T, Robertson S, Scott D, et al. Host species restriction of Middle East respiratory syndrome coronavirus through its receptor, dipeptidyl peptidase 4. Journal of virology. 2014;88(16):9220-32. doi:10.1128/JVI.00676-14.

58. Agrawal AS, Garron T, Tao X, Peng BH, Wakamiya M, Chan TS, et al. Generation of a transgenic mouse model of Middle East respiratory syndrome coronavirus infection and disease. Journal of virology. 2015;89(7):3659-70. doi:10.1128/JVI.03427-14. Description of an essential transgenic mouse model for preclinical evaluation of MERS vaccines.

59. Li K, Wohlford-Lenane C, Perlman S, Zhao J, Jewell AK, Reznikov LR, et al. Middle East respiratory syndrome coronavirus causes multiple organ damage and lethal disease in mice transgenic for human dipeptidyl peptidase 4 . The Journal of infectious diseases. 2016;213(5):712-22. doi:10.1093/infdis/jiv499.

60. Tao X, Garron T, Agrawal AS, Algaissi A, Peng BH, Wakamiya M, et al. Characterization and demonstration of the value of a lethal mouse model of Middle East respiratory syndrome coronavirus infection and disease. Journal of virology. 2016;90(1):57-67. doi:10.1128/JVI.02009-15.

61. Tao X, Garron T, Agrawal AS, Algaissi A, Peng BH, Wakamiya M, et al. Characterization and demonstration of the value of a lethal mouse model of Middle East respiratory syndrome coronavirus infection and disease. Journal of virology. 2015;90(1):57-67. doi:10.1128/JVI.02009-15. 